\title{
The prognostic value of serum procalcitonin measurements in critically injured patients: a systematic review
}

Aziza N. AlRawahi ${ }^{1 *} \mathbb{D}$, Fatma A. AlHinai ${ }^{1}$, Christopher J. Doig ${ }^{2}$, Chad G. Ball ${ }^{1,3}$, Elijah Dixon ${ }^{1}$, Zhengwen Xiao ${ }^{3}$ and Andrew W. Kirkpatrick ${ }^{1,2,3}$

\begin{abstract}
Background: Major trauma is associated with high incidence of septic complications and multiple organ dysfunction (MOD), which markedly influence the outcome of injured patients. Early identification of patients at risk of developing posttraumatic complications is crucial to provide early treatment and improve outcomes. We sought to evaluate the prognostic value of serum procalcitonin (PCT) levels after trauma as related to severity of injury, sepsis, organ dysfunction, and mortality.

Methods: We searched PubMed, MEDLINE, EMBASE, the Cochrane Database, and references of included articles. Two investigators independently identified eligible studies and extracted data. We included original studies that assessed the prognostic value of serum PCT levels in predicting severity of injury, sepsis, organ dysfunction, and mortality among critically injured adult patients.
\end{abstract}

Results: Among 2015 citations, 19 studies (17 prospective; 2 retrospective) met inclusion criteria. Methodological quality of included studies was moderate. All studies showed a strong correlation between initial PCT levels and Injury Severity Score (ISS). Twelve out of 16 studies demonstrated significant elevation of initial PCT levels in patients who later developed sepsis after trauma. PCT level appeared a strong predictor of MOD in seven out of nine studies. While two studies did not show association between PCT levels and mortality, four studies demonstrated significant elevation of PCT levels in non-survivors versus survivors. One study reported that the PCT level of $\geq 5 \mathrm{ng} / \mathrm{mL}$ was associated with significantly increased mortality (OR 3.65; 95\% Cl 1.03-12.9; $p=0.04$ ).

Conclusion: $\mathrm{PCT}$ appears promising as a surrogate biomarker for trauma. Initial peak PCT level may be used as an early predictor of sepsis, MOD, and mortality in trauma population.

Keywords: Procalcitonin, Prognosis, Trauma, Injuries, Critical care, Intensive care unit

\section{Introduction}

Trauma is the leading cause of death during the first four decades of life and the third leading cause of death overall, across all age groups $[1,2]$. Each year, trauma accounts for 41 million emergency department visits and 2.3 million hospital admissions in the USA. Of these, 192,000 die as a result of their injuries [2]. The triphasic peaks of death after injury have long been described epidemiologically.

\footnotetext{
* Correspondence: aziza.alrawahi@gmail.com

${ }^{1}$ Department of Surgery, University of Calgary and the Foothills Medical Centre, North Tower 10th Floor, 1403-29th St. NW, Calgary, Alberta T2N 2T9, Canada

Full list of author information is available at the end of the article
}

Essentially, catastrophic non-survivable injuries occur at the time of injury, with subsequent airway obstruction, respiratory failure, and especially hemorrhage predominating as the second peak. The recognition of non-recoverable head injury and especially sepsis/systemic inflammatory response syndrome-related deaths constitute the third [3, 4]. Although the global burden of traumatic death is ominous in its predicted future increase as the developing world mechanizes, great strides have recently been made in addressing both the primary peak with injury prevention and safety conscious designs, and in the second peak related to dramatic advances in resuscitation for hemorrhage, among other interventions $[5,6]$. Progress in improving the

(C) The Author(s). 2019 Open Access This article is distributed under the terms of the Creative Commons Attribution 4.0 International License (http://creativecommons.org/licenses/by/4.0/), which permits unrestricted use, distribution, and 
outcomes of posttraumatic sepsis/SIRS is urgently required. Sepsis remains a major challenge in critically injured patients with an incidence range between 2 and 17\% during the posttraumatic period, with associated mortality rates reaching as high as $23 \%$ [7].

Major trauma provokes a strong systemic inflammatory response syndrome (SIRS) early after traumatic injury as a result of tissue damage, hypotension, hypoxia, cytokine release, and inflammation [8]. The prognosis is strongly related to the posttraumatic balance between pro- and antiinflammatory responses [9-12]. Following this induction of the inflammatory cascade is an increase in counter regulatory anti-inflammatory cytokines, which subsequently results in immunosuppression and increased susceptibility to infection and complications such as sepsis. Together, the consequence of initial injury and inflammation, subsequent immune suppression and infection, results in multiple organ dysfunction (MOD) or multiple organ failure (MOF) $[9,12]$. MOD/MOF unfortunately remains the leading cause of late death following trauma [13].

Early identification of patients at risk of developing posttraumatic complications is crucial to allow the provision of early and appropriate therapy for sepsis. It has been demonstrated that prompt and appropriate management of sepsis prevents MOD, reduces mortality, and improves clinical outcomes $[14,15]$. Thus, any test or clinical information that facilitates an earlier diagnosis or safely triggers the earlier appropriate treatment of sepsis may save lives. Past research has explored a number of some inflammatory markers for their prognostic value, but no clear message regarding what, if any, marker to rely on has emerged, despite promise [16-18].

This is especially true with regard to measurement of serum procalcitonin (PCT) levels, which has been of recent interest as a potential and more accurate marker of sepsis in critically ill patients. PCT is a 116-amino acid polypeptide precursor of calcitonin produced by the $\mathrm{C}$ cells of the thyroid gland. Healthy individuals typically have serum PCT levels less than $0.05 \mathrm{ng} / \mathrm{ml}$. In response to bacterial endotoxins or pro-inflammatory cytokines such as interleukin-6 (IL-6) and tumor necrosis factor alpha (TNF- $\alpha$ ), various cell types outside the thyroid gland produce PCT, resulting in up to a 1000 -fold increase in levels $[19,20]$. These PCT increases occur with severe inflammation, including systemic infection and especially severe sepsis [21-23]. PCT levels are thus closely related to the severity of systemic inflammation, with higher levels associated with severe sepsis, and potentially most importantly, declining levels are associated with the resolution of infection [24]. Given these unique characteristics and reliable kinetics, PCT level has emerged as a promising biomarker. Therefore, it has been suggested that serum PCT level determination may be superior to previously studied biomarkers for use in the diagnosis of sepsis, monitoring sepsis course and severity, and guiding antimicrobial therapy [16, 18, 25-27].

However, in heterogeneous populations of critically ill patients, the results concerning PCT performance remain conflicting. Therefore, in this review, we attempt to extend the scope of previous reviews by evaluating the prognostic value of serum PCT levels, in a more homogenous group of critically injured adult patients, as related to severity of injury, sepsis, organ dysfunction, and mortality.

\section{Materials and methods \\ Search strategy}

A systematic literature search was performed in accordance with the Preferred Reporting Items for Systematic Reviews and Meta-Analyses (PRISMA) Group [28] using the following databases from their inception to September 2018: PubMed, Ovid MEDLINE, EMBASE, and the Cochrane Library (see the completed PRISMA checklist in Additional file 1). Medical Subject Heading terms and keywords for procalcitonin, trauma, injury, prognosis, and predictive value were used. The search was limited to original studies on human subjects, published in the English language. Our complete search strategies are shown in Additional file 2. To identify other potentially relevant articles, the PubMed "related articles" feature was utilized and the two authors independently hand-searched the reference list of included articles and relevant reviews for additional citations.

\section{Study selection}

Two reviewers (A.N.AR. and F.A.AH.) independently screened the titles and abstracts of all identified citations for potential eligibility. The following inclusion criteria were applied: (1) study participants (adults $\geq 16$ years old trauma patients), (2) intervention (single or serial measurements of serum procalcitonin level from day of admission to trauma center or intensive care unit (ICU) following trauma), (3) comparison of prognostic performance of PCT levels compared to other potential biomarkers, (4) outcome (documentation of at least one of the outcomes of sepsis, organ dysfunction, mortality, or correlation of PCT with severity of injury), and (5) cohort or case-control study design.

Reviews, case reports, letters, conference abstracts, and editorials were excluded. Articles involving isolated injury to the central nervous system and pediatric or burn trauma were also excluded. Full-text articles of identified abstracts that were relevant with the inclusion criteria were assessed for final eligibility. The agreement between the two reviewers was assessed using Kappa statistic for the inter-rater reliability [29].

\section{Data extraction}

Two reviewers (A.N.AR. and F.A.AH) independently extracted data using a standardized recording tool to record 
the study design and setting, year of publication, country of origin, number of study participants, participant clinical characteristics, PCT testing system, kinetics of PCT, markers other than PCT, and study outcomes.

We defined the terms "SIRS" and "Sepsis" according to the American College of Chest Physician/Society for Critical Care Medicine [30], which supported definition of SIRS, sepsis, and severe sepsis as most studies were published prior to the release of Sepsis-3 [31].

\section{Methodological quality assessment}

The risk of bias of the included studies was assessed by two independent investigators (A.N.AR. and F.A.AH) using the Quality in Prognosis Studies (QUIPS) tool developed by Hayden et al. [32]. This tool consists of 30 criteria divided into six domains: patient selection, study attrition, prognostic factor measurement, outcome measurement, confounding measurement and account, and statistical analysis and reporting. Each criterion was scored using "yes," "no," or "unclear." This scoring led to the overall judgment of "low," "moderate," or "high" risk of bias per domain. We considered a study to be of high quality when the bias was rated as low or moderate with respect to almost all of the domains. Conversely, a study was considered to be of low quality when the bias was rated high in most of the bias domains. Disagreements were resolved by consensus.

\section{Results}

\section{Literature search}

Figure 1 presents a flow diagram of study identification and subsequent inclusion. Among 2015 citations identified by the search, 19 studies fit the inclusion criteria including 4146 patients with multiple trauma. There was an excellent inter-investigator agreement on the inclusion of full-

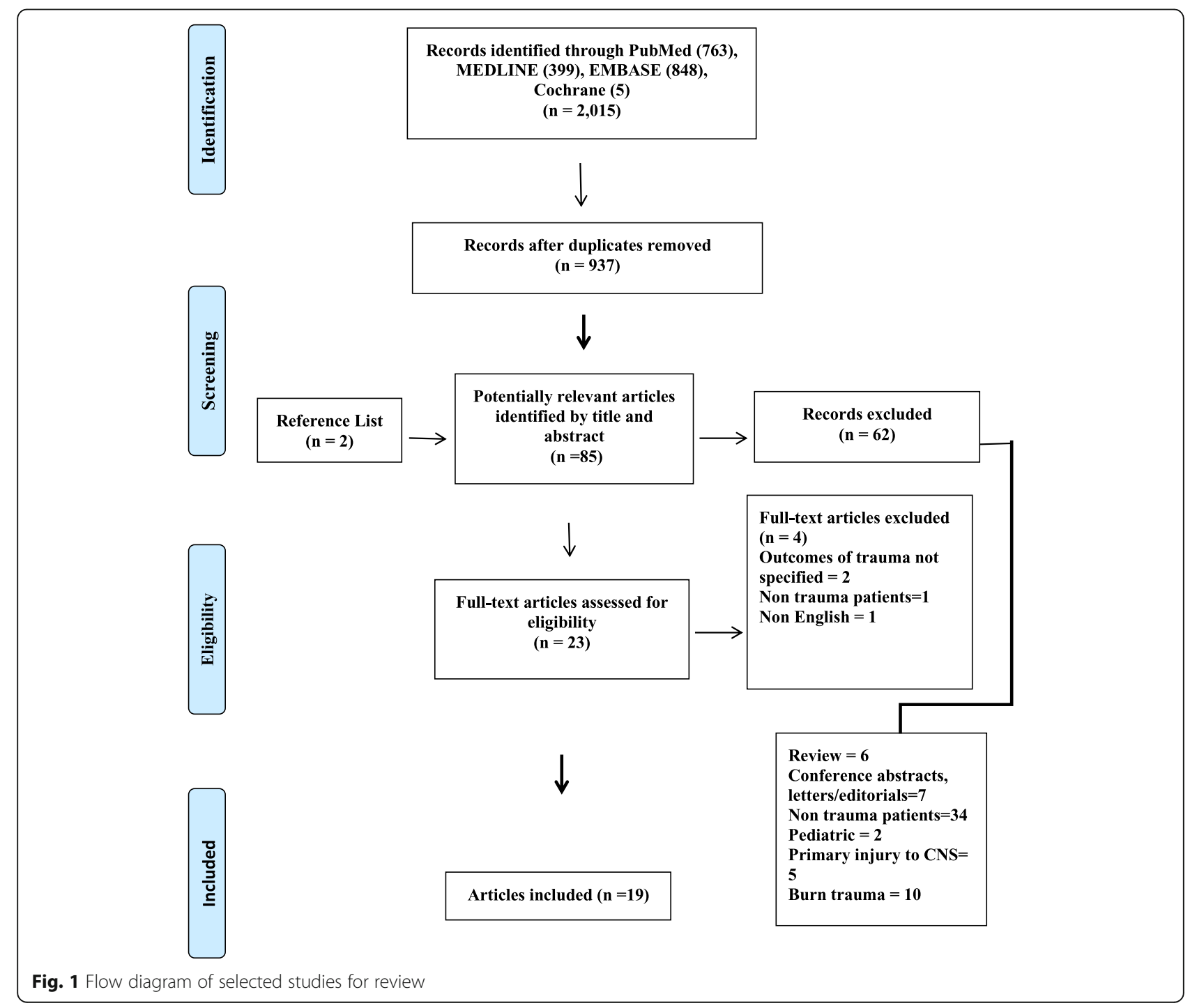


text articles in the systematic review $(\kappa$ statistic $=0.88$; 95\% CI $=0.65-1.00$ ).

Due to heterogeneity between studies with respect to definition of clinical outcomes and statistical methods, it was not possible to statistically pool the results. Instead, findings were reported descriptively.

\section{Characteristics of the included studies}

Table 1 details the characteristics of the included studies. The included studies were published from 1998 to 2016, while the majority were published after 2006 (13/ 19; 68.4\%). Sixteen studies were conducted in Europe $[34,37-51](84.2 \%)$, two were conducted in Asia [33, 35]
(10.5\%), and one was conducted in the USA [36] (5.2\%). All studies were observational and non-interventional. Eleven studies were prospective cohort [34, 36-39, 41$43,45,46,51]$, six studies were prospective case-control [33, 35, 44, 47-49], one study was retrospective cohort study [40], and one study was retrospective case-control [50].

All studies evaluated the role of PCT in predicting at least one clinical outcome in critically injured patients (Fig. 2). Twelve studies (63.3\%) were conducted in the critical care units $[35-37,39,40,42-45,48,50,51]$. Overall, the aggregate study population included a total of 4146 patients with trauma in whom serum PCT levels

Table 1 Details of study characteristics of included studies

\begin{tabular}{|c|c|c|c|c|c|c|c|c|}
\hline \multirow[t]{2}{*}{ Study } & \multirow[t]{2}{*}{ Study design } & \multirow[t]{2}{*}{ Study setting } & \multirow[t]{2}{*}{$\begin{array}{l}\text { No. of } \\
\text { patients }\end{array}$} & \multirow[t]{2}{*}{ Mortality \% } & \multirow[t]{2}{*}{$\begin{array}{l}\text { Peak PCT } \\
\text { level }\end{array}$} & \multicolumn{3}{|c|}{$\begin{array}{l}\text { PCT level predicting } \\
\text { outcomes }\end{array}$} \\
\hline & & & & & & Sepsis & MODS & Death \\
\hline Ren et al. [33] (China, 2016) & Prospective case-control & $\begin{array}{l}\text { Trauma surgical } \\
\text { department }\end{array}$ & 56 & - & $\begin{array}{l}\text { Days } 1 \\
\text { and } 2\end{array}$ & Yes & - & - \\
\hline $\begin{array}{l}\text { Wojtaszek et al. [34] (Poland, } \\
\text { 2014) }\end{array}$ & Prospective cohort & - & 45 & $\begin{array}{l}\text { Data not } \\
\text { shown }\end{array}$ & Day 1 & No & - & Yes \\
\hline $\begin{array}{l}\text { Rajkumari et al. [35] (India, } \\
\text { 2013) }\end{array}$ & Prospective case-control & SICU & 275 & 10 & - & Yes & No & - \\
\hline Sakran et al. [36] (USA, 2012) & Prospective cohort & Trauma ICU & 102 & 13 & $\begin{array}{l}\text { Days } 1 \\
\text { and } 2\end{array}$ & Yes & - & Yes \\
\hline $\begin{array}{l}\text { Haasper et al. [37] (Germany, } \\
\text { 2010) }\end{array}$ & Prospective cohort & $\mathrm{ICU}$ & 94 & 12 & $\begin{array}{l}\text { Days } 2 \\
\text { and } 3\end{array}$ & No & Yes & - \\
\hline $\begin{array}{l}\text { Keel et al. [38] (Switzerland, } \\
\text { 2009) }\end{array}$ & Prospective cohort & Trauma center & 83 & 12 & Day 1 & Yes & - & - \\
\hline Castelli et al. [39] (Italy, 2009) & Prospective cohort & $\mathrm{ICU}$ & 94 & 5 & Day 1 & Yes & Yes & - \\
\hline $\begin{array}{l}\text { Billeter et al. [40] (Switzerland, } \\
\text { 2009) }\end{array}$ & Retrospective cohort & $\mathrm{SICU}$ & 1032 & 10 & Day 1 & Yes & - & - \\
\hline $\begin{array}{l}\text { Maier et al. [41] (Germany, } \\
\text { 2009) }\end{array}$ & Prospective cohort & - & 74 & - & Day 1 & - & - & - \\
\hline Balci et al. [42] (Turkey, 2009) & Prospective cohort & SICU & 113 & 44 & $\begin{array}{l}\text { Days } 1 \\
\text { and } 7\end{array}$ & Yes & - & Yes \\
\hline Castelli et al. [43] (Italy, 2006) & Prospective cohort & $\mathrm{ICU}$ & 49 & - & Day 1 & Yes & Yes & - \\
\hline $\begin{array}{l}\text { Ertugrul et al. [44] (Turkey, } \\
\text { 2006) }\end{array}$ & Prospective case-control & $\mathrm{SICU}$ & 41 & - & - & No & - & - \\
\hline $\begin{array}{l}\text { Meisner et al. [45] (Germany, } \\
\text { 2006) }\end{array}$ & Prospective cohort & $\mathrm{ICU}$ & 90 & 17 & Day 1 & Yes & No & Yes \\
\hline $\begin{array}{l}\text { Egger et al. [46] (Austria, } \\
\text { 2004) }\end{array}$ & Prospective cohort & $\mathrm{ICU}$ & 26 & - & - & Yes & - & - \\
\hline $\begin{array}{l}\text { Hensler et al. [47] (Germany, } \\
\text { 2003) }\end{array}$ & Prospective case-control & Trauma center & 137 & 11 & $\begin{array}{l}\text { Days } 1+2 \\
\text { combined }\end{array}$ & No & Yes & No \\
\hline $\begin{array}{l}\text { Andermahr et al. [48] } \\
\text { (Germany, 2002) }\end{array}$ & Prospective case-control & $\mathrm{ICU}$ & 133 & 21 & Day 1 & No & - & - \\
\hline $\begin{array}{l}\text { Oberholzer et al. [49] } \\
\text { (Switzerland, 2000) }\end{array}$ & Prospective case-control & Trauma center & 1276 & 7 & Day 1 & Yes & Yes & - \\
\hline $\begin{array}{l}\text { Wanner et al. [50] } \\
\text { (Germany, 2000) }\end{array}$ & Retrospective case-control & $\mathrm{ICU}$ & 405 & 23 & $\begin{array}{l}\text { Days } 1 \text { and } \\
3\end{array}$ & Yes & Yes & No \\
\hline $\begin{array}{l}\text { Mimoz et al. [51] (France, } \\
\text { 1998) }\end{array}$ & Prospective cohort & $\mathrm{SICU}$ & 21 & 14 & Day 1 & No & Yes & - \\
\hline
\end{tabular}




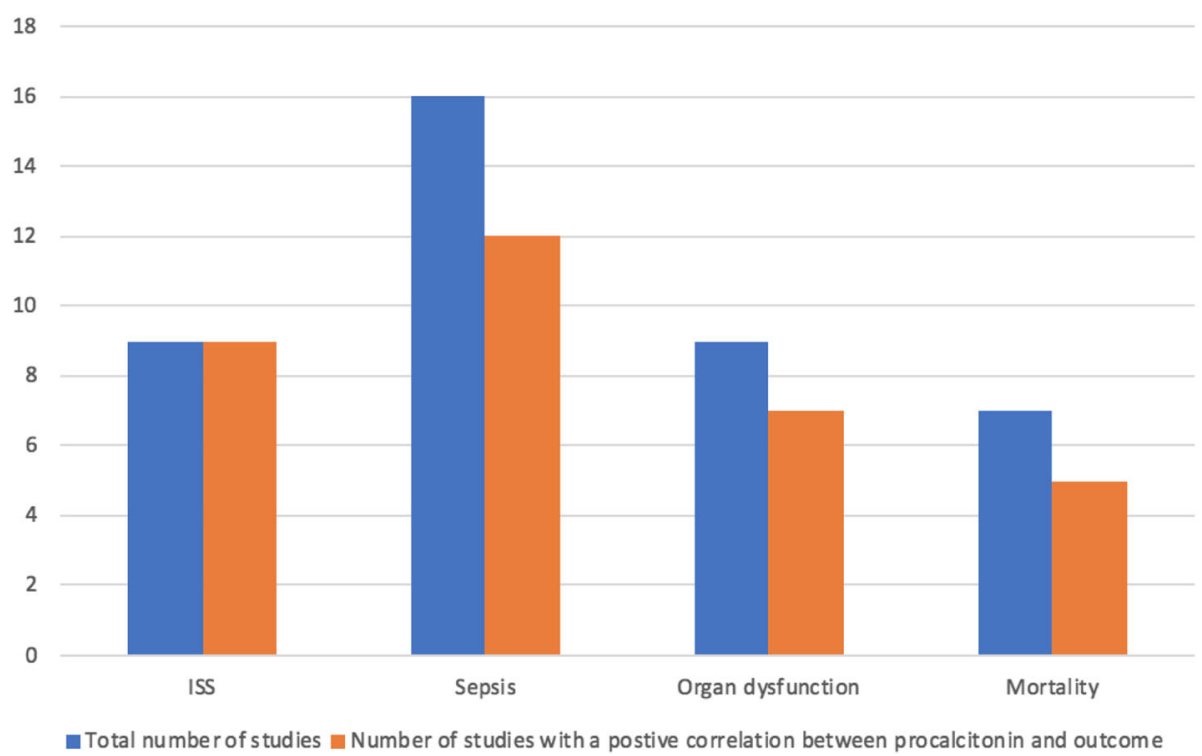

Fig. 2 Studies evaluated the role of procalcitonin levels in predicting clinical outcomes following trauma

were used to predict posttraumatic complications. The mean age ranged between 34 and 49 years. The mean injury severity score ranged from 21 to 32 . The mechanism of injury was blunt and/or penetrating trauma. All studies were civilian, with none comprising military populations or combat injuries.

\section{Risk of bias assessment}

Figure 3 summarizes the risk of bias assessment for all included studies. Most studies were assessed to be of low to moderate risk of bias. Nine studies demonstrated high risk of bias in at least one domain [33-35, 37, 39, $41,42,44,46]$. Study confounding domain was deemed to be at moderate to high risk of bias in 14 studies (73.7\%) [33-35, 37-46, 51]. The majority did not account for potential confounding factors in the study designs and/or made adjustment for the effects of the confounders in the analysis, while $21.1 \%$ of these studies did not name any confounder [35, 43, 44, 46]. The risk of bias was moderate to high in the domain of statistical analysis in 10 studies (52.6\%) [33-35, 37, 39, 41, 42, 44, $46,51]$. Only 7 studies used statistical models to assess prognostic relationships [36, 37, 40-42, 45, 47]. In one study, mortality data were presented in graph only [34].

\section{Kinetics of PCT}

PCT levels were measured from the serum sample in all studies, using immunoluminometric assay (LUMItest) in 11 studies (57.8\%) [38, 40, 42-45, 47-51] and Kryptor Assay in 3 studies $(15.7 \%)$ [36, 37, 41]. Other techniques used to determine PCT levels were Roche Cobas e 411 [33], VIDAS system [35], enzyme-linked fluorescent immunoassay (ELFA) [34], and chemiluminescence analyzer
[39]. Most studies showed rapid kinetics of PCT levels with peak levels reached on day 1 post trauma [33, 36, $38-43,45,47-51]$, and to a lesser extent on day $2[34,37]$. PCT levels declined rapidly thereafter towards the normal range. Sakran et al. [36] and Haasper et al. [37] demonstrated that a biphasic rise in PCT after day 7 was associated with development of sepsis.

\section{Correlation between PCT levels and injury severity and injury pattern}

Nine studies $(47.4 \%)[33,39,41,42,45-47,50,51]$ assessed the correlation between initial PCT level and the severity of injury using Injury Severity Score (ISS) [52]. All studies showed a correlation between initial PCT levels and ISS. When patients were categorized into those with severe trauma (ISS $>20$ ) or moderate trauma (ISS $<20$ ), the initial PCT was significantly higher in patients with severe trauma [41, 42, 45, 50].

Four studies assessed the association between PCT level and injury pattern, three of which showed that serum levels of PCT were higher among patients with abdominal injury $[35,41,45]$, whereas one study showed no correlation between PCT level and injury pattern [50].

\section{The value of serum PCT levels in differentiating sepsis from non-infectious systemic inflammation in injured patients}

Sixteen studies (84.2\%) assessed the utility of serum PCT level as a marker for sepsis [33, 35-40, 42-50]. In patients who developed systemic or septic complications, the kinetic of PCT was similar to those without complications. After reaching the peak level on day 1 after trauma, an immediate decline was observed towards normal range [36, 


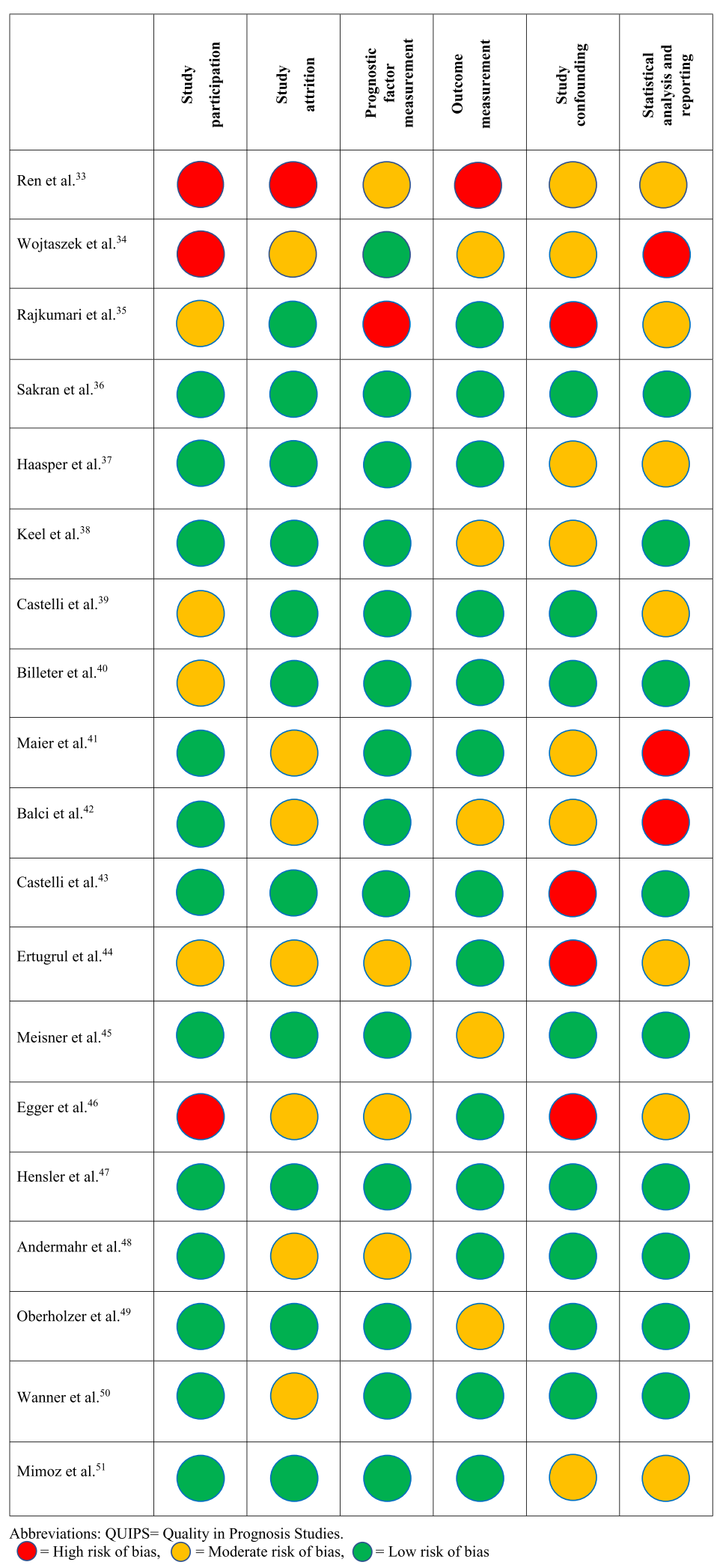

Fig. 3 Assessment of risk of bias using QUIPS tool 
$38,40,45,50]$. However, the initial peak PCT was significantly higher in patients who subsequently developed sepsis compared to those without sepsis and the difference remained significant between the two groups during the study period [33, 36, 38-41, 45, 46, 49, 50]. Further, patients who developed sepsis demonstrated a significant increase of peak PCT levels compared with patients with non-infectious systemic inflammation $[36,42,43,50]$. Because the severity of injury itself can significantly influence circulating PCT levels, Wanner et al. demonstrated a 3.9fold increase of initial peak PCT levels in injured patients with sepsis compared with patients with SIRS [50]. In addition, in a subgroup analysis of injured patients with low ISS (ISS $<25)$ compared with patients with high ISS (ISS $\geq 25$ ), PCT levels remained significantly elevated in patients with sepsis compared with patients without sepsis in those subgroups [50]. Castelli et al. observed a significant increase in PCT level in trauma patients at day of sepsis diagnosis as compared with levels measured on day 1 before the diagnosis [39]. Rajkumari et al. reported that all patients with serum PCT level $>2 \mathrm{ng} / \mathrm{ml}$ developed infections after trauma [35]. Three studies measured the sensitivity and specificity for the diagnosis of sepsis as compared with non-infectious systemic inflammation. With cutoff point of procalcitonin level of $1.5 \mathrm{ng} / \mathrm{mL}$, the sensitivity to detect sepsis ranged from 42 to $76 \%$. In those same studies, the specificity ranged from 73 to $77 \%[45,47,50]$.

The most common identified sources of infection resulting in sepsis were the lungs $[36,39,40,42,43,45,48,50]$, bloodstream [36, 39, 40, 42, 43, 45], urinary tract infection $[36,39,40,45,48]$, soft tissue infection $[39,42,43,45,48$, 50], peritonitis [39, 43, 45, 50], and bacterial meningitis $[43,50]$. However, four studies reported no significant difference in the PCT level between patients who developed sepsis and those who did not [37, 44, 47, 48], although one study evaluated the predictive value of PCT level for the development of posttraumatic pneumonia and reported higher PCT levels among patients who developed pneumonia compared with those without, but the difference did not reach significance [44].

\section{The value of serum PCT levels in predicting the future occurrence of MODS in injured patients}

Nine studies (47.4\%) assessed the utility of serum PCT level in predicting the future occurrence of MOD and/or MOF in injured patients [35, 37, 39, 43, 45, 47, 49-51]. Studies used either the Sequential Organ Failure Assessment (SOFA) [53] or the Multiple Organ Failure Score developed by Goris to assess the severity of organ dysfunction [54, 55]. Seven studies demonstrated significantly higher initial PCT levels in patients who subsequently developed MODS compared to those patients without MODS [37, 39, 43, 47, 49-51]. Haasper et al. observed an elevated PCT level preceding the development of MODS by 3 days [37]. Hensler et al. divided patients with MOF into early and late MOF using day 3 as a cutoff point to avoid biased results by patients who developed MOF already on day 1 . Results remained significant for both groups when compared with patients without MOF [47]. However, two studies showed no correlation between PCT levels and severity of organ dysfunction $[35,45]$.

\section{The value of serum PCT levels in predicting mortality in injured patients}

Among seven studies assessing the value of procalcitonin serum level determination in predicting death following trauma, three studies demonstrated significant elevation of PCT levels in non-survivors compared with that in survivors $[34,42,45]$. The difference in PCT level between the two groups remained significant during the first week after trauma in two of those studies [42, 45]. Meisner et al. showed that by the end of the first week, the difference between survivors and non-survivors increased up to 15 -fold in patients with fatal outcome [45]. A study by Sakran et al. demonstrated significantly increased mortality among patients with a PCT level of $\geq 5 \mathrm{ng} / \mathrm{ml}$ compared with that of patients with less than $5 \mathrm{ng} / \mathrm{ml}$, with odds ratio of 3.65 (95\% CI 1.23-4.61, $p=$ 0.01) [36]. Conversely, two studies reported no association between PCT level and fatal outcome $[47,50]$.

\section{Prognostic value performance of PCT levels compared to other potential biomarkers}

Fourteen studies (73.7\%) assessed serum PCT levels and other biomarkers simultaneously to predict posttraumatic complications (Table 2). Five studies demonstrated slow induction of C-reactive protein (CRP) after trauma with peak levels reaching on day 3 after trauma [38-40, 43, 45]. PCT was superior to CRP in predicting septic complications in these studies.

Interleukin 6 (IL-6) has similar kinetics to those of PCT. IL-6 increases during the early phase after trauma with peak levels reached on day 0 after trauma [37, 38, 40, 49]. While Billeter et al. observed a significant difference in IL6 levels between patients who developed sepsis and those who did not on days 3 and 5 after trauma [40], Keel et al. observed this difference only after day 5 [38].

Haasper et al. demonstrated low sensitivity of IL-6 for predicting sepsis and low specificity for predicting both sepsis and MODS [37].

\section{Discussion}

Serious traumatic injuries often induce an early overwhelming systemic inflammation and a late immune paralysis that can disrupt immune system homeostasis and predispose patients to septic complications with an ultimately fatal outcome. Ongoing international efforts have produced substantial progress into understanding 
Table 2 Prognostic values of other biomarkers studied simultaneously with serum PCT levels

\begin{tabular}{|c|c|c|}
\hline Study & Other biomarkers & Comments on other biomarkers \\
\hline Ren et al. [33] & HSP70, WBC & $\begin{array}{l}\text { - HSP70 and WBC levels were elevated at } 1-6 \mathrm{~h} \text { post injury while PCT increased } \\
24 \mathrm{~h} \text { post } \\
\text { - Magnitude of HSP70 increased was related to the severity of injury } \\
\text { - Increased HSP70 } 24 \mathrm{~h} \text { post injury suggested infection }\end{array}$ \\
\hline Rajkumari et al. [35] & CRP & $\begin{array}{l}\text { - No difference in CRP levels between patients with and without sepsis } \\
\text { - PCT and CRP did not correlate with SOFA score }\end{array}$ \\
\hline Haasper et al. [37] & IL-6 & $\begin{array}{l}\text { - IL-6 levels peaked on day 0, while PCT peaked levels peaked on day } 1 \\
\text { - Significant difference in IL-6 and PCT levels between patients with and without } \\
\text { MODS } \\
\text { - No difference in IL-6 and PCT levels between patients with and without sepsis }\end{array}$ \\
\hline Keel et al. [38] & PSP, CRP, IL-6 & $\begin{array}{l}\text { - Significant difference in PSP levels between patients with and without sepsis } \\
\text { during hospital stay } \\
\text { - Slow induction of CRP with peak levels reaching day } 3 \text {. Significant difference in } \\
\text { CRP levels between patients with and without sepsis on day } 7 \text { after trauma } \\
\text { - Peak IL-6 levels of day } 0 \text { after trauma. Significantly higher IL-6 levels in septic } \\
\text { patients after day } 5 \text { compared to patients with no infection } \\
\text { - Peak PCT on day } 1 \text {. Significant PCT levels between patients with sepsis and } \\
\text { without on days } 1,3,5,7 \text {, and } 14 \\
\text { - No difference in CRP, PCT, and IL-6 levels between patients with sepsis and } \\
\text { local infection }\end{array}$ \\
\hline Castelli et al. [39] & CRP & $\begin{array}{l}\text { - No difference in CRP levels between patients with and without sepsis } \\
\text { - CRP did not correlate with SOFA score }\end{array}$ \\
\hline Billeter et al. [40] & CRP, IL-6, lactate & $\begin{array}{l}\text {-IL-6 peaked on day } 1 \text { after trauma } \\
\text { - Significant difference in IL-6 levels between patients with or without sepsis } \\
\text { on days } 3 \text { and } 5 \text {. No difference after day } 5 \\
\text { - Slow induction of CRP with peak levels reaching between days } 3 \text { and } 7 \\
\text { - Significant difference in CRP levels between patients with or without sepsis } \\
\text { on days } 5,7 \text {, and } 14 \\
\text { - Insufficient } 24 \text {-h lactate clearance was associated with high rate of mortality } \\
\text { and sepsis }\end{array}$ \\
\hline Balci et al. [42] & CRP & $\begin{array}{l}\text { - CRP levels were higher only in cases of severe sepsis or septic shock, but not } \\
\text { in cases of sepsis alone } \\
\text { - Significant difference in CRP level between survivors and non-survivors on days } \\
1 \text { and } 7\end{array}$ \\
\hline Castelli et al. [43] & CRP & $\begin{array}{l}\text { - Slow induction of CRP after trauma } \\
\text { - No correlation between CRP levels and sepsis } \\
\text { - CRP levels correlated with SOFA score }\end{array}$ \\
\hline Ertugrul et al. [44] & CRP & - No difference in CRP levels between infected and non-infected groups \\
\hline Meisner et al. [45] & CRP & $\begin{array}{l}\text { - CRP levels peaked on day } 3 \text { (slow induction) } \\
\text { - No correlation between CRP levels and posttraumatic complications including sepsis, } \\
\text { MODS, and mortality }\end{array}$ \\
\hline Egger et al. [46] & $\begin{array}{l}\text { PMN migration, CRP, IL-6, IL-8, NT, } \\
\text { lactate, cortisol, Elastase, MDA }\end{array}$ & $\begin{array}{l}\text { - PMN migration was a highly sensitive predictive marker for infection } \\
\text { - No difference in the other biomarker levels between infected and non-infected groups }\end{array}$ \\
\hline Hensler et al. [47] & Neopetrin (NT) & $\begin{array}{l}\text { - NT level decreased on day } 0 \text { after trauma, followed by an increase on days } 1 \text { and } 2 \\
\text { - Both PCT and NT were unable to differentiate between patients who developed sepsis } \\
\text { or not } \\
\text { - No difference between PCT or NT levels of survivors and non-survivors } \\
\text { - No difference in NT levels between patients with and without MOF }\end{array}$ \\
\hline $\begin{array}{l}\text { Oberholzer et al. } \\
\text { [49] }\end{array}$ & IL-6 & $\begin{array}{l}\text { Both PCT and IL-6 levels peaked on day } 1 \text { after trauma } \\
\text { Both PCT and IL- } 6 \text { levels were significantly higher in septic patients compared with } \\
\text { patients without sepsis } \\
\text { Both PCT and IL-6 levels were significantly higher in patients who developed MODS } \\
\text { compared with patients without MODS }\end{array}$ \\
\hline Mimoz et al. [51] & CRP & $\begin{array}{l}\text { - PCT levels peaked on day } 1 \text { while CRP levels peaked on day } 2 \text { after trauma } \\
\text { - Both peak PCT and CRP levels were higher in patients who subsequently developed } \\
\text { MODS }\end{array}$ \\
\hline
\end{tabular}

Abbreviations: HAI hospital-acquired infection, CRP C-reactive protein, IL interleukin, PCT procalcitonin, NT neopetrin, PMN polymorphonuclear leucocyte, PSP pancreatic stone protein, SOFA sequential organ failure assessment, MODS multiple organ dysfunction syndrome, MDA malondialdehyde 
how trauma affects the immune system, although the overall picture is confusing and still in its relative infancy. Nonetheless, irrespective of the exact molecular mechanisms involved, it remains true that the basic principle of initiating appropriate antibiotics early while searching for and correcting the source of septic complications will save lives [56]. However, the indiscriminate use of broad-spectrum antibiotics based on the mere chance that a patient may be developing sepsis cannot be justified, and such practices have grave implications for all of the critically ill/injured in the future. Thus, a biomarker that may help identify patients who are either developing or at high risk for developing sepsis before this becomes otherwise clinically apparent might ameliorate such adverse outcomes following trauma.

Since its first description in 1993 by Assicot et al., authors have described a strong and generally consistent association between serum PCT level and the subsequent clinical course of severely traumatized patients [24]. Early elevation of PCT is related to the severity of trauma and magnitude of tissue injury. Trauma patients with SIRS have initially elevated levels of PCT. However, PCT levels are only mildly elevated in non-infectious SIRS. Significantly elevated PCT levels correlate with a substantially increased risk for septic complications. Observational studies have shown that most patients with non-infectious SIRS have an inflammatory-mediated procalcitonin level ranges from 0.3 to $0.8 \mathrm{ng} / \mathrm{mL}$ [5760], while studies on septic patients (from any source) in an ICU setting have shown PCT levels range from 4.5 to $12.0 \mathrm{ng} / \mathrm{mL}$ [61-64]. In addition, rapid decline to normal levels most often indicates resolution of systemic inflammation/infection. Therefore, under these circumstances, the initial peak PCT level can reliably differentiate between infectious and non-infectious SIRS in critically injured patients and hence outperform other biomarkers such as C-reactive protein and IL-6 [65, 66]. Since the increase in PCT level usually precedes the onset of clinical symptoms, it allows earlier detection of infection than the conventional standard methods.

In our review, four studies did not demonstrate an association between PCT level and development of sepsis. The variability in the results might be related to the lack of consistency in defining sepsis and lack of consensus gold standard for defining infection per se. This could have misclassified patients as having systemic inflammation if potentially infected patients did not exhibit clinical signs or in whom bacterial cultures were negative. In the study of Ertugul et al., a single time point PTC was used to predict the development of hospital-acquired infection (HAI) [44]. However, given the complexity of the immune response after trauma which is influenced by both patient-specific factors and injury-specific factors, one single parameter may not be able to adequately predict the clinical course. Andermahr et al. reported no significant difference in PCT levels between patients with or without pneumonia [48]. However, not every patient with an infection is septic. Studies have shown that PCT levels are significantly higher in patients with sepsis than those with an isolated pulmonary infection [67].

Sepsis and MOF are the predominant cause of late death in trauma [13]. A review by Ciriello et al. reported the usefulness of PCT level in predicting sepsis course in trauma population, thus allowing early diagnosis of MODS [18]. Our review suggests there is also utility of PCT level in predicting mortality. In this group of patients, early recognition of septic complications through the use of a specific and rapid marker for infection and hence early therapeutic decision may have an impact on survival and improve outcomes. In our reviews, most studies demonstrated a significant increase in early PCT level in non-survivors compared with survivors after trauma. Two studies did not show an association between PCT level and late mortality. In the study of Wanner et al., the incidence of sepsis was low (11.1\%) and $70 \%$ of the deaths occurred less than $72 \mathrm{~h}$ after trauma [50]. In the study of Hensler et al., a small number of patients died after trauma [47]. Furthermore, the time frames in the definition of mortality varied across studies; some studies used ICU mortality, whereas other studies used 28-day mortality. These limitations could probably preclude achieving a substantial difference. Nevertheless, sepsis is clearly associated with high mortality. Studies have found that the mortality from trauma-related sepsis is significantly higher than mortality from trauma alone $[68,69]$. PCT has been shown to reflect the prognosis of sepsis in septic patients. Svoboda et al. observed a tendency to reduce mortality rate in septic patients after multiple trauma or major surgery using PCT in guiding early re-intervention [70].

To our knowledge, this is the first systematic review to comprehensively assess the prognostic value of PCT level in relation to four outcomes including severity of injury, development of sepsis and MODS, and mortality in trauma patients. Most studies in our review were prospective, which allowed the study of the kinetics of PCT level from day 0 post trauma, and its association with the occurrence of complications later in the subsequent clinical course, hence accurately assessing the prognostic value of PCT level.

This review has several limitations. We did not include non-English publications in our review. Studies conducted in mixed Medical-Surgical ICU that included trauma cohort were excluded due to combined data. The quality of the primary studies varied with main issue related to confounding variables. Statistical methods used in the outcome assessment varied across studies, which made combining results in a meta-analysis difficult, which certainly represents a drawback of the current review. There 
was lack of a consensus definition of the term, severe trauma. This could induce a high heterogeneity among trauma patients due to variations in the immunological responses depending on the injury pattern.

\section{Conclusions}

Despite the limitations identified during this review, PCT seems to hold promise as a surrogate biomarker for trauma. Initial peak PCT level may be used as an early predictor of severity of injury, development of sepsis and MOD, and mortality in trauma population. Serum PCT levels may contribute to the identification of patients who may benefit most from more aggressive management. However, further studies, preferably prospective randomized controlled multicenter open-label intervention trials, are necessary to investigate the impact of procalcitonin-guided decision-making on the clinical outcomes in the trauma setting.

\section{Supplementary information}

Supplementary information accompanies this paper at https://doi.org/10. 1186/s13054-019-2669-1.

Additional file 1. Preferred Reporting Item for Systematic Reviews and Meta-Analysis (PRISMA) checklist.

Additional file 2. Search strategies.

\section{Abbreviations}

APATCHE: Acute Physiology And Chronic Health Evaluation; CRP: C-reactive protein; ELFA: Enzyme-linked fluorescent immunoassay; HAl: Hospitalacquired infection; IAH: Intra-abdominal hypertension; ICU: Intensive care unit; IL: Interleukin; ISS: Injury Severity Score; MDA: Malondialdehyde; MOD: Multiple organ dysfunction; MODS: Multiple organ dysfunction syndrome; MOF: Multiple organ failure; NT: Neopetrin; OR: Odds ratio; PCT: Procalcitonin; PMN: Polymorphonuclear leucocyte; PRISMA: Preferred Reporting Item for Systematic Reviews and Meta-Analysis; PSP: Pancreatic stone protein; QUIPS: Quality in Prognosis Studies; SIRS: Systemic inflammatory response syndrome; SOFA: Sequential Organ Failure Assessment; TNF-a: Tumor necrosis factor alpha

\section{Acknowledgements}

None.

\section{Additional information}

Meeting presentation: This study was presented as poster presentation at Trauma 2016: The Trauma Association of Canada Annual Scientific Meeting in Halifax, Nova Scotia, Canada on May 6, 2016.

Work attributed to the Department of Surgery, University of Calgary, Calgary, Alberta, Canada

\section{Authors' contributions}

ANAR and FAAH conceived and designed the study and created the study protocol, which was critically revised by AWK. ANAR and FAAH performed the literature search, full-text screening, and data extraction. ANAR and FAAH performed the risk of bias assessment. ANAR wrote the manuscript, which was reviewed and edited by all other authors. The study was supervised by AWK. All authors reviewed and approved the final manuscript.

\section{Funding}

No funding to declare.
Availability of data and materials

ANAR and FAAH had full access to all data in the study and take responsibility for the integrity of the data and the accuracy of the data analyses.

Ethics approval and consent to participate

Not applicable.

Consent for publication

Not applicable.

\section{Competing interests}

AWK has received funding from Kinetic Concepts Incorporated for a randomized controlled trial comparing the ABThera ${ }^{\mathrm{TM}}$ Open Abdomen Negative Pressure Therapy system and Barker's vacuum pack temporary abdominal closure techniques. He has also received travel funding from LifeCell Corp., Syntheses, and Innovative Trauma Care. The other authors declare that they have no competing interests.

\section{Author details}

${ }^{1}$ Department of Surgery, University of Calgary and the Foothills Medical Centre, North Tower 10th Floor, 1403-29th St. NW, Calgary, Alberta T2N 2T9, Canada. ${ }^{2}$ Department of Critical Care Medicine, University of Calgary, Ground Floor McCaig Tower, 3134 Hospital Drive NW, Calgary, Alberta T2N 5A1, Canada. ${ }^{3}$ Regional Trauma Program, University of Calgary and the Foothills Medical Centre, 1403-29th St. NW, Calgary, Alberta T2N 2T9, Canada.

Received: 15 July 2019 Accepted: 12 November 2019

Published online: 03 December 2019

\section{References}

1. Rhee $P$, Joseph $B$, Pandit $V$, et al. Increasing trauma deaths in the United States. Ann Surg. 2014;260(1):13-21.

2. Centers for Disease Control and Prevention, National Center for Injury Prevention and Control. Web-based Injury Statistics Query and Reporting System (WISQARS) [online] [2014] Available from URL: https://www.cdc.gov/ injury/wisqars/.

3. Trunkey DD. Trauma. Accidental and intentional injuries account for more years of life lost in the U.S. than cancer and heart disease. Among the prescribed remedies are improved preventive efforts, speedier surgery and further research. Sci Am. 1983;249(2):28-35.

4. Baker CC, Oppenheimer L, Stephens B, et al. Epidemiology of trauma deaths. Am J Surg. 1980;140(1):144-50.

5. Murray CJ, Vos T, Lozano R, et al. Disability-adjusted life years (DALYs) for 291 diseases and injuries in 21 regions, 1990-2010: a systematic analysis for the Global Burden of Disease Study 2010. Lancet. 2012;380:2197-223.

6. Lozano R, Naghavi M, Foreman K, et al. Global and regional mortality from 235 causes of death for 20 age groups in 1990 and 2010: a systematic analysis for the Global Burden of Disease Study 2010. Lancet. 2012;380:2095-128.

7. Mann EA, Baun MM, Meininger JC, et al. Comparison of mortality associated with sepsis in the burn, trauma, and general intensive care unit patient: a systematic review of the literature. Shock. 2012;37(1):4-16.

8. Moore FA, Moore EE. Evolving concepts in the pathogenesis of postinjury multiple organ failure. Surg Clin North Am. 1995;75(2):257-77.

9. Bone RC. Sir Isaac Newton, sepsis, SIRS, and CARS. Crit Care Med. 1996;24(7): $1125-8$

10. Bone RC. Toward a theory regarding the pathogenesis of the systemic inflammatory response syndrome: what we do and do not know about cytokine regulation. Crit Care Med. 1996;24(1):163-72.

11. Talmor M, Hydo L, Barie PS. Relationship of systemic inflammatory response syndrome to organ dysfunction, length of stay, and mortality in critical surgical illness: effect of intensive care unit resuscitation. Arch Surg. 1999;134(1):81-7.

12. Keel M, Trentz O. Pathophysiology of polytrauma. Injury. 2005;36(6):691-709.

13. Pfeifer R, Tarkin IS, Rocos B, et al. Patterns of mortality and causes of death in polytrauma patients--has anything changed? Injury. 2009;40(9):907-11.

14. Balci C, Sungurtekin $H$, Gürses $E$, et al. Usefulness of procalcitonin for diagnosis of sepsis in the intensive care unit. Crit Care. 2003;7(1):85-90.

15. Dellinger RP, Levy MM, Rhodes A, et al. Surviving sepsis campaign: international guidelines for management of severe sepsis and septic shock: 2012. Crit Care Med. 2013;41(2):580-637. 
16. Xiao Z, Wilson C, Robertson HL, Roberts DJ, Ball CG, Jenne CN, Kirkpatrick AW. Inflammatory mediators in intra-abdominal sepsis or injury - a scoping review. Crit Care. 2015;19(1):373.

17. Jin $\mathrm{H}$, Liu Z, Xiao $Y$, et al. Prediction of sepsis in trauma patients. Burns Trauma. 2014;2(3):106-13.

18. Ciriello V, Gudipati S, Stavrou PZ, Kanakaris NK, Bellamy MC, Giannoudis PV. Biomarkers predicting sepsis in polytrauma patients: current evidence. Injury. 2013;44(12):1680-92.

19. Schneider HG, Lam QT. Procalcitonin for the clinical laboratory: a review. Pathology. 2007;39(4):383-90.

20. Benoist JF, Mimoz O, Assicot M, et al. Serum procalcitonin, but not C-reactive protein, identifies sepsis in trauma patients. Clin Chem. 1998:44(8 Pt 1):1778-9.

21. Kafetzis DA, Velissariou IM, Nikolaides $P$, et al. Procalcitonin as a predictor of severe appendicitis in children. Eur J Clin Microbiol Infect Dis. 2005;24:484-7.

22. Nylén ES, Snider RH, Thompson BS, et al. Pneumonitis-associated hyperprocalcitonemia. Am J Med Sci. 1996;312:12-8.

23. Meisner M, Tschaikowsky K, Hutzler A, et al. Postoperative plasma concentration of procalcitonin after different types of surgery. Intensive Care Med. 1998:24:680-4

24. Assicot M, Gendrel D, Carsin H, et al. High serum procalcitonin concentrations in patients with sepsis and infection. Lancet. 1993;341(8844):515-8.

25. Uzzan B, Cohen R, Nicolas $P$, et al. Procalcitonin as a diagnostic test for sepsis in critically ill adults and after surgery or trauma: a systematic review and meta-analysis. Crit Care Med. 2006;34(7):1996-2003.

26. Sridharan $\mathrm{P}$, Chamberlain RS. The efficacy of procalcitonin as a biomarker in the management of sepsis: slaying dragons or tilting at windmills? Surg Infect. 2013:14(6):489-511.

27. Jensen JU, Hein L, Lundgren B, et al. Procalcitonin And Survival Study (PASS) Group. Procalcitonin-guided interventions against infections to increase early appropriate antibiotics and improve survival in the intensive care unit: a randomized trial. Crit Care Med. 2011;39(9):2048-58.

28. Moher D, Liberati A, Tetzlaff J, et al. Preferred reporting items for systematic reviews and meta-analyses: the PRISMA statement. Int J Surg. 2010;8(5):336-41.

29. Landis JR, Koch GG. The measurement of observer agreement for categorical data. Biometrics. 1977;33(1):159-74.

30. American College of Chest Physicians/Society of Critical Care Medicine Consensus Conference: definitions for sepsis and organ failure and guidelines for the use of innovative therapies in sepsis. Crit Care Med. 1992;20(6):864-74.

31. Singer M, Deutschman CS, Seymour CW, et al. The third international consensus definitions for sepsis and septic shock (Sepsis-3). JAMA. 2016; 315(8):801-10.

32. Hayden JA, Côté $P$, Bombardier C. Evaluation of the quality of prognosis studies in systematic reviews. Ann Intern Med. 2006;144(6):427-37.

33. Ren B, Zou G, Huang Y, et al. Serum levels of HSP70 and other DAMP proteins can aid in patient diagnosis after traumatic injury. Cell Stress Chaperones. 2016;21(4):677-86.

34. Wojtaszek M, Staśkiewicz G, Torres K, et al. Changes of procalcitonin level in multiple trauma patients. Anaesthesiol Intensive Ther. 2014;46(2):78-82.

35. Rajkumari N, Mathur P, Sharma S, et al. Procalcitonin as a predictor of sepsis and outcome in severe trauma patients: a prospective study. J Lab Physicians. 2013;5(2):100-8

36. Sakran JV, Michetti CP, Sheridan MJ, et al. The utility of procalcitonin in critically ill trauma patients. J Trauma Acute Care Surg. 2012;73(2):413-8.

37. Haasper C, Kalmbach M, Dikos GD, et al. Prognostic value of procalcitonin (PCT) and/or interleukin-6 (IL-6) plasma levels after multiple trauma for the development of multi organ dysfunction syndrome (MODS) or sepsis. Technol Health Care. 2010;18(2):89-100.

38. Keel $M$, Härter $L$, Reding $T$, et al. Pancreatic stone protein is highly increased during posttraumatic sepsis and activates neutrophil granulocytes. Crit Care Med. 2009:37(5):1642-8.

39. Castelli GP, Pognani C, Cita M, et al. Procalcitonin as a prognostic and diagnostic tool for septic complications after major trauma. Crit Care Med. 2009;37(6):1845-9

40. Billeter A, Turina M, Seifert B, et al. Early serum procalcitonin, interleukin-6, and 24-hour lactate clearance: useful indicators of septic infections in severely traumatized patients. World J Surg. 2009;33(3):558-66.

41. Maier $M$, Wutzler $S$, Lehnert $M$, et al. Serum procalcitonin levels in patients with multiple injuries including visceral trauma. J Trauma. 2009;66(1):243-9.

42. Balci C, Sivaci R, Akbulut $G$, et al. Procalcitonin levels as an early marker in patients with multiple trauma under intensive care. J Int Med Res. 2009; 37(6):1709-17.
43. Castelli GP, Pognani C, Cita M, et al. Procalcitonin, C-reactive protein, white blood cells and SOFA score in ICU: diagnosis and monitoring of sepsis. Minerva Anestesiol. 2006;72(1-2):69-80.

44. Ertugrul BM, Yilmabasar A, Ertugrul O, et al. Do C-reactive protein and procalcitonin predict hospital-acquired infection in patients with trauma? Saudi Med J. 2006;27(4):560-2.

45. Meisner M, Adina H, Schmidt J. Correlation of procalcitonin and C-reactive protein to inflammation, complications, and outcome during the intensive care unit course of multiple-trauma patients. Crit Care. 2006;10(1):R1.

46. Egger $\mathrm{G}$, Aigner R, Glasner A, et al. Blood polymorphonuclear leukocyte migration as a predictive marker for infections in severe trauma: comparison with various inflammation parameters. Intensive Care Med. 2004;30(2):331-4

47. Hensler T, Sauerland S, Lefering R, et al. The clinical value of procalcitonin and neopterin in predicting sepsis and organ failure after major trauma. Shock. 2003:20(5):420-6.

48. Andermahr J, Greb A, Hensler T, et al. Pneumonia in multiple injured patients: a prospective controlled trial on early prediction using clinical and immunological parameters. Inflamm Res. 2002;51(5):265-72.

49. Oberholzer A, Keel M, Zellweger R, et al. Incidence of septic complications and multiple organ failure in severely injured patients is sex specific. $J$ Trauma. 2000:48(5):932-7.

50. Wanner GA, Keel M, Steckholzer U, et al. Relationship between procalcitonin plasma levels and severity of injury, sepsis, organ failure, and mortality in injured patients. Crit Care Med. 2000;28(4):950-7.

51. Mimoz O, Benoist JF, Edouard AR, et al. Procalcitonin and C-reactive protein during the early posttraumatic systemic inflammatory response syndrome. Intensive Care Med. 1998;24(2):185-8.

52. Civil ID, Schwab CW. The Abbreviated Injury Scale, 1985 revision: a condensed chart for clinical use. J Trauma. 1988;28(1):87-90.

53. Vincent JL, Moreno R, Takala J, et al. The SOFA (Sepsis-related Organ Failure Assessment) score to describe organ dysfunction/failure. On behalf of the Working Group on Sepsis-Related Problems of the European Society of Intensive Care Medicine. Intensive Care Med. 1996;22(7):707-10.

54. Goris RJ, te Boekhorst TP, Nuytinck JK, et al. Multiple-organ failure Generalized autodestructive inflammation? Arch Surg. 1985;120(10):1109-15.

55. Lefering R, Goris RJ, van Nieuwenhoven EJ, et al. Revision of the multiple organ failure score. Langenbeck's Arch Surg. 2002;387(1):14-20.

56. Levy MM, Dellinger RP, Townsend SR, et al. The Surviving Sepsis Campaign: results of an international guideline-based performance improvement program targeting severe sepsis. Crit Care Med. 2010;38(2):367-74.

57. Nakajima A, Yazawa J, Sugiki D, et al. Clinical utility of procalcitonin as a marker of sepsis: a potential predictor of causative pathogens. Intern Med. 2014;53:1497-503.

58. Castelli GP, Pognani C, Meisner M, et al. Procalcitonin and C-reactive protein during systemic inflammatory response syndrome, sepsis and organ dysfunction. Crit Care. 2004;8:R234-42.

59. Meynaar I, Droog W, Batstra M, et al. In critically ill patients, serum procalcitonin is more useful in differentiating between sepsis and SIRS than CRP, II-6, or LBP. Crit Care Res Pract. 2011;2011:594-645.

60. Deng $\mathrm{S}$, Zhu H, Wang K, et al. Procalcitonin as a marker of sepsis and outcome in patients with neurotrauma: an observation study. BMC Anesthesiol. 2013;13:48-51.

61. Nobre $\mathrm{V}$, Harbarth $\mathrm{S}$, Jean-Daniel $\mathrm{G}$, et al. Use of procalcitonin to shorten antibiotic treatment duration in septic patients: a randomized trial. Am J Respir Crit Care Med. 2008;177:498-505.

62. Schroeder $\mathrm{S}$, Hochreiter M, Koehler T, et al. Procalcitonin (PCT)-guided algorithm reduces length of antibiotic treatment in surgical intensive care patients with severe sepsis: results of a prospective randomized study. Arch Surg. 2009;394:221-6.

63. Hochreiter M, Kohler T, Schweiger AM, et al. Procalcitonin to guide duration of antibiotic therapy in intensive care patients: a randomized prospective controlled trial. Crit Care. 2009:13(R83):1-7.

64. Bouadma L, Luyt CE, Tubach $F$, et al. Use of procalcitonin to reduce patients' exposure to antibiotics in intensive care units (PRORATA trial): a multicenter randomized controlled trial. Lancet. 2010;375:463-74.

65. Mitaka C. Clinical laboratory differentiation of infectious versus noninfectious systemic inflammatory response syndrome. Clin Chim Acta. 2005; 351(1-2):17-29.

66. Meynaar IA, Droog W, Batstra M, et al. In critically ill patients, serum procalcitonin is more useful in differentiating between sepsis and SIRS than CRP, II-6, or LBP. Crit Care Res Pract. 2011;2011:594645. 
67. Carr JA. Procalcitonin-guided antibiotic therapy for septic patients in the surgical intensive care unit. J Intensive Care. 2015;3(1):36.

68. Osborn TM, Tracy JK, Dunne JR, et al. Epidemiology of sepsis in patients with traumatic injury. Crit Care Med. 2004;32(11):2234-40.

69. Plurad DS, Lustenberger T, Kilday P, et al. The association of race and survival from sepsis after injury. Am Surg. 2010;76(1):43Y47.

70. Svoboda P, Kantorová I, Scheer P, Radvanova J, Radvan M. Can procalcitonin help us in timing of re-intervention in septic patients after multiple trauma or major surgery? Hepatogastroenterology. 2007;54(74):359-63.

\section{Publisher's Note}

Springer Nature remains neutral with regard to jurisdictional claims in published maps and institutional affiliations.

Ready to submit your research? Choose BMC and benefit from:

- fast, convenient online submission

- thorough peer review by experienced researchers in your field

- rapid publication on acceptance

- support for research data, including large and complex data types

- gold Open Access which fosters wider collaboration and increased citations

- maximum visibility for your research: over $100 \mathrm{M}$ website views per year

At $\mathrm{BMC}$, research is always in progress.

Learn more biomedcentral.com/submissions 